http://dx.doi.org/10.12795/PH.1989.v04.i02.02

\title{
LA PALABRA POÉTICA EN JUSTO JORGE PADRÓN
}

\section{Fernando Rodríguez-Izquierdo Gavala}

El tema de la Poética de Justo Jorge Padrón es aparentemente claro y obvio, ya que el mismo autor, en los prólogos de su Obra poética ${ }^{1}$ y de La visita del mar y Los dones de la tierra ${ }^{2}$, se ha preocupado de proporcionar a sus lectores las pistas necesarias.

El empeño no es en realidad tan fácil, pues desentrañar los secretos de esta señera voz, en la que confluyen otras igualmente señeras, como son la de Bécquer, Vicente Aleixandre, Pablo Neruda, Jorge Luis Borges, etc., sin que en ningún momento la palabra de Justo Jorge Padrón pierda su timbre propio, no deja de ser un reto.

Si Ezra Pound perseguía la síntesis de Dante y Whitman, Justo Jorge Padrón nos manifiesta que llega a la poesía por el deseo de «conseguir una voz personal» ${ }^{3}$ en la que lleguen a encontrarse las perfecciones que se dan dispersas en varios admirables autores, pero que ninguno reúne de forma absoluta:

«¿Cómo encontrar una obra que tuviera el aleteo metafísico de Rilke con la pasión sensual y deslumbrante de Neruda? ¿En cuál la luminosidad cósmica y telúrica de Aleixandre con la sobria expresividad de Quasimodo o Ungaretti? ¿Dónde hallar contrastados el misterio mágico de Lorca con las visiones más dramáticas de Lautréamont o Blake? ¿Cómo fundir los destellos aéreos y terrestres de Hölderlin, Keats, Lundkvist, Trakl o Saint-John Perse con la sorpresa de Bull o Mandelstam? ¿En qué frontera unir el dramatismo de Pessoa, Lindegren o Pavese con el rigor y la finura expresiva de Cernuda o de Paz?» ${ }^{4}$.

1 Justo Jorge Padrón: Obra Poética 1971-1980 (Citaremos OP). Selecciones de Poesía Española. Plaza y Janés (Barcelona, 1980).

2 Justo Jorge Padrón: La visita del mar (1980-1984). Los dones de la tierra (1982-1983) (Citaremos VM.) Selecciones Austral. Espasa Calpe (Madrid, 1984).

3 OP, 12.

4 OP, 12-13. 
Este texto nos patentiza, al mismo tiempo que las devociones de Justo Jorge Padrón, el espíritu internacional de su poesía, que persigue el íntimo latir del ser humano dondequiera que este se encuentre, sin conocer más fronteras que las que impone la misma naturaleza. Por otra parte, sería difícil afirmar críticamente que nuestro autor ha alcanzado su objetivo de deseada síntesis. Pero lo que sí me parece evidente es que no ceja en el recto camino de dar cima a su ambición, y que - aunque él tendrá la suficiente sabiduría para no darse nunca por satisfecho con su obra - nos ofrece la esperanza cierta de conseguir tan ansiada síntesis que -insisto- no dejará nunca de ser su voz personal.

Entrando ya en el tema, vengamos a desarrollar lo que, con un nuevo sentido respecto al ya consagrado de Carlos Bousoño, yo llamaría «el cuadrilátero lírico» de Justo Jorge Padrón.

«Cuadrilátero» es un término que puede traernos connotaciones de lucha libre o boxeo y, por cierto, el quehacer poético envuelve en no pequeño grado una lucha con el lenguaje. No obstante, superando estas posibles connotaciones, vamos a centrarnos en el valor denotativo del término: «cuatro lados». La poesía presenta siempre cuatro lados, facetas o vertientes de paralelo interés: Emoción, Idea, Imagen y Lenguaje.

Es teoría que he oído exponer oralmente a Justo Jorge Padrón, con el fuego -y ya salió otro término sagrado; no «oscuro fuego», sino «luminoso fuego»que lo caracteriza, y que encuentro también desarrollada en su obra, tanto desde el punto de vista teórico como desde el práctico.

En el prólogo ya citado nos dice Justo Jorge Padrón:

«Por otro lado, lejos de mis coetáneos, los venecianos y novísimos, que surgieron a finales de la década del sesenta, me he esforzado por hacer una poesía sustantiva y de síntesis que concediera igual importancia al lenguaje, la emoción humana, el concepto y la imaginación. Por ello estuve de acuerdo con el criterio de Octavio Paz de que «la esencia de lo poético es la fijación de un instante en la percepción». La conmoción que nos produce ese momento elegido entre todos, es precisamente lo que para mí constituye el núcleo de la revelación; puesto que la vida en esa fracción de tiempo se paraliza y nuestra conciencia ve y oye al mundo en su verdad esencial.

Este estado intensificado nos lo remite la lucidez poética de la conciencia visionaria, que alcanza el mayor grado de fusión de su individualidad con el cosmos o con esa intuición que de él tenemos» ${ }^{5}$.

Hasta aquí nuestro autor, tras hacer mención de lo que hemos denominado «el cuadrilátero», como también hará en el prólogo de La visita del mar ${ }^{6}$, y desarrollará líricamente en el poema "Cartografía del poema»" ha expuesto su concepción de la poesía como una unidad de percepción instantánea de la realidad, por un camino intuitivo que en nada difiere - a mi modo de ver- de la iluminación budista o «satori» (dicho en lengua japonesa). Y aunque no he conse-

5 OP, 15.

6 VM, 69-76. Más concretamente, p. 71.

7 VM, 146. 
guido ninguna cita "padroniana» — permítaseme el adjetivo- de autores orientales, me consta el interés con que Justo Jorge Padrón sigue las manifestaciones de esa compleja cultura.

Por otro lado, las palabras «revelación», «verdad esencial», nos hablan de un transfondo religioso que yo no calificaría de oriental ni de occidental, sino que es simplemente la mística propia de toda poesía transcedente y universal que ronde el misterio de la existencia. Además, el adjetivo «visionario» aplicado a «conciencia» nos evoca uno de sus procedimientos formales más queridos: la imagen visionaria.

A continuación, y siguiendo la cita interrumpida, Justo Jorge Padrón nos da una de sus definiciones de poesía:

«La poesía es la vida más intensa hacia el conocimiento último —conocimiento inasequible a la reflexión lógica- pues sólo mediante la intuición poética llega el hombre al misterio» ${ }^{8}$.

Poesía, pues, como vía de «conocimiento de la realidad más profunda», camino imprescindible para llegar a «la verdad del Todo al que pertenecemos». «Transcendencia del yo lírico hacia una fusión con el misterio universal», «en un secreto y gozoso panteísmo».

Nos debe resultar ya asequible la brillante síntesis a la que aboca nuestro autor:

«Poesía, en su aparición más deslumbrante y verdadera, es fundar la revelación».

No cabe duda, de que nuestro más alto poeta místico, San Juan de la Cruz, suscribiría esta afirmación «desde otra ladera», usando la frase de Dámaso Alonso. El «panteísmo» de Justo Jorge Padrón es — huelga decirlo— un punto de partida de actitudes estéticas y vitales, más que estrictamente religiosas. Es, como él dice, un «secreto» panteísmo (aunque proclamado a voces).

\section{Emoción.}

Siguiendo una tendencia bien expresada en la estética japonesa ${ }^{9}$, la emoción de una obra literaria no consiste en hablar de la emoción, sino en que el texto sea emocionante de por sí: es decir, que transmita una emoción del autor al lector.

No obstante, me permitiré citar dos textos en que Justo Jorge Padrón habla de la emoción. El primero es poético, y forma parte del poema que dedica a Arthur Lundkvist en homenaje por su setenta cumpleaños: "Como un roble encendido o un sueño de volcán» —-según reza el comienzo del poema- «allá sigue en el norte su emoción de caminos».

Parece consubstancial al poeta la emoción. También en el prólogo de su Obra poética podemos destacar un texto en prosa. Cuando el poeta comenta el paso estilístico que supone Otesnita sobre El abedul en llamas, dice:

8 OP, 15.

9 Keene, Donald: Japanese Literature. Charles E. Tuttle Co. (Tokyo, 1. ed, 1955), p. 8. 
«La voluntad insistía en la renovación adjetival, el tránsito del yo hacia la pluralidad indecible, así como en la persistencia de un lenguaje sensorializado que quiere huir de abstracciones y ofrecer a cambio la sensualidad y la emoción de los mágicos instantes de la dicha y la congoja amorosas» ${ }^{10}$.

Se trata pues de transmitir la emoción de la verdad vivida. El poeta no cree en las afirmaciones «a priori», pues las ve carentes de credibilidad. En consecuencia, aboga por escribir «no con preceptos, sino con post-ceptos, como diría Unamuno» ${ }^{11}$. Y añade Justo Jorge Padrón:

«Resultaría redundante afirmar mi creencia en la inspiración, pero aún creo más en el minucioso y constante trabajo por dominar y guardar en su verdad futura, ese magma que nos deja de súbito el fulgor de la intuición poética. Artista $\mathrm{y}$ artesano juntos e indivisibles hacia un mismo fin» ${ }^{12}$.

\section{Idea.}

Ya hemos aludido al interés de nuestro autor por cultivar la poesía como forma de conocimiento. A propósito de Los oscuros fuegos nos dirá:

«Poesía que parte de la experiencia y del conocimiento de la vida por reflejar el mundo del hombre. Ahondamiento de la meditación en el dolor» ${ }^{13}$.

La obra de Justo Jorge Padrón es una toma de conciencia sobre la condición humana. Si en sus tres primeros libros Los oscuros fuegos, Mar de la noche y Los círculos del infierno, predomina una visión existencialista que frecuentemente linda con la desesperación, en El abedul en llamas y en Otesnita contemplamos una especie de redención por el amor, volcado respectivamente —según los libroshacia la naturaleza y hacia la mujer. Amor que, como nos recuerda el autor en un poema palpitante de sabiduría vivida, debe entenderse «nunca con posesión» ${ }^{14}$, como reza el título del mismo.

La irrecuperabilidad del pasado afecta también a la memoria del amor. No obstante, el poema representa un momento de redención - concepto este también muy religioso- en ese caos.

La naturaleza tiene su lenguaje — se nos habla por ejemplo de «El mar y su escritura» ${ }^{15}$, de «el lenguaje violento / de las flores» ${ }^{16}$ - como también tiene su lenguaje la muerte ${ }^{17}$. Y dentro de esta concepción es posible imaginar «que la intemperie acalle su dominio / de dalia amortajada y afluya hacia un paisaje / cuya

10 OP, 17.

11 OP, 19.

12 Ibíd.

13 OP, 13.

14 OP, 283. También: Justo Jorge Padrón: Otesnita. Ed. Prometeo (Valencia, 1979), p. 111.

15 VM, 87-88.

16 OP, 277. Véase también VM, 172.

17 VM, 166. 
insistencia siempre nos redime» ${ }^{18}$; así como la aurora se convierte «en esta redención de la mirada» ${ }^{19}$; así como el canto del gallo «redime la vida aún dormida» ${ }^{20}$.

Redención de nuestra contingencia que radica en el uso de la palabra poética, puesto que para ese "prisionero perpetuo» que cada uno de nosotros es, «la libertad es siempre la palabra» ${ }^{21}$. «Palabra fundadora que se apropia del mundo ${ }^{22}$; o bien, siguiendo en el empleo de terminología religiosa, palabra como resurrección:

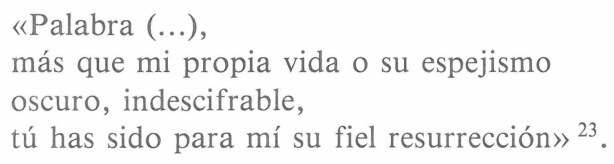

Esta palabra que en una concepción becqueriana, derivada de la famosa Rima 1, es como «un himno gigante y extraño» del cosmos, cuyas «cadencias» recoge el poema:

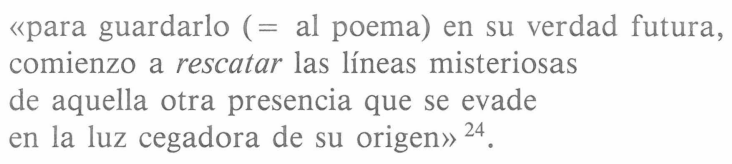

La naturaleza escribe su poesía, como hemos dicho; y en este punto se nos revela una nueva afinidad de Justo Jorge Padrón con la estética oriental ${ }^{25}$. Libélulas, abejas, «huéspedes» «de las frondas» crean un «cancionero»:

«El cancionero dulce que sus huéspedes crean es para ti, también es tuyo en este instante» ${ }^{26}$.

Por ello no debe de extrañarnos que el elemento fuego, al que habla el autor diciéndole:

«Infatigable fuiste en mi poema

el más intenso símbolo de vida» ${ }^{27}$,

se nos describa como «escritura rotunda» ${ }^{28}$, y que se nos hable de

18 VM, 132. El subrayado es mío, así como cualquier otro subrayado que desde ahora aparezca en las citas.

19 VM, 119.

20 VM, 85.

$21 \mathrm{VM}, 158$.

22 VM, 119.

23 VM, 109.

24 OP, 203.

25 Keene, o.c., p. 22.

26 VM, 198.

27 VM, 211.

28 Ibíd. 
«esa inextinguible permanencia

de montañas y ríos y raíces

cuyo horizonte escribe la distancia» ${ }^{29}$.

A esta luz, también puede resultarnos familiar comprender que exista una «lluvia con sílabas azules» ${ }^{30}$, o unas «voces (...) penetrando las aguas» ${ }^{31}$, o que las aguas traigan «un susurro de luz amanecida / con sus vocales blancas de la mano» ${ }^{32}$; e incluso que el poeta llegue a reconocer que es la naturaleza quien escribe su poema. En «Madre tierra» (de El abedul en llamas ${ }^{33}$ ), el poeta se dirige a la naturaleza en estos términos:

«desde un claro rincón

de tu cuerpo terrestre,

como un testigo más

de la fugaz estancia,

escribes mi poema».

He aquí la identificación hombre-naturaleza, tan propia de la mística oriental.

En ese universo el poeta pretende «seguir la búsqueda / de un florido prodigio» ${ }^{34}$, aunque por desgracia frecuentemente se encuentra «condenado a apresar únicamente / unos escasos peces disecados» ${ }^{35}$.

\section{Imagen.}

En un texto de Otesnita, Justo Jorge Padrón nos habla de la imagen, y al mismo tiempo pone en práctica una fulgurante imagen visionaria:

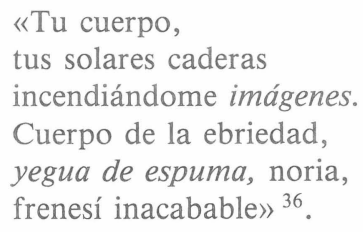

«Tu cuerpo, tus solares caderas incendiándome imágenes.

Cuerpo de la ebriedad, yegua de espuma, noria, frenesí inacabable» ${ }^{36}$.

El autor mismo declara que ya «en Mar de la noche se concede más importancia (que en Los oscuros fuegos) a la imagen y la metáfora como forma esencial del poema en el sentido que señalara Lundkvist de «iluminar, establecer contactos y situaciones imprevistas y ampliar la conciencia» ${ }^{37}$.

\footnotetext{
29 VM, 136.

30 VM, 99.

31 VM, 140.

32 VM, 114.

33 OP, 183.

34 VM, 154.

$35 \mathrm{VM}, 133$.

36 OP, 253.

37 OP, 14.
} 
Verdaderamente, el salto mortal que supone la metáfora obliga a conocer la realidad de una manera nueva. La metáfora puede aumentar su impacto por dos caminos conocidos: la imagen visionaria y la alegoría. Sin embargo, Justo Jorge Padrón nos ofrece aún más: la imagen fantasmagórica y la imagen proliferante. Pero vayamos por partes.

La imagen visionaria rompe el ya tenue vínculo lógico que mantenía la metáfora con la realidad, para adentrarse en el dominio de la irracionalidad. Es más bien una sensación que una idea lo que liga la palabra al concepto. Así, en el ejemplo recién citado, describir el cuerpo femenino como «yegua de espuma» entra dentro de esa categoría; o bien cuando dice:

«El mar y su escritura depositan como una rosa verde de agua y fuego

los más bellos secretos en nuestras manos ávidas» ${ }^{38}$.

Versos estos que, por otra parte, confirman nuestras afirmaciones anteriores. No es extraño que Justo Jorge Padrón vea en el lenguaje un venero de visiones, y nos hable de «el árbol visionario del idioma» ${ }^{39}$. Es pues del mayor interés

«la conciencia de ver ahora el mundo

con el intenso vuelo

de la imaginación en la palabra» ${ }^{40}$.

En resumen: Justo Jorge Padrón nos dice que

«El ir edificando mi lar poético con la vertebración de la metáfora y la imagen visionaria, creo que es lo que en parte, singulariza a mi poesía» ${ }^{41}$.

En cuanto a la alegoría o metáfora continuada, es del mayor interés como ejemplo el poema titulado «El visitante», de La visita del mar ${ }^{42}$, cuyo preludio creo ver en el también magistral poema «Como quien surge del otoño» de Mar de la noche ${ }^{43}$. Otro precioso ejemplo puede ser «El naufragio» de Los círculos del infierno ${ }^{44}$, donde la lluvia de maletas sobre la calle combina el elemento visionario con la imagen alegórica.

La imagen fantasmagórica aparece formulada en la Introducción que Leopoldo de Luis hace a La visita del mar. Los dones de la tierra. Es una imagen eminentemente sobrerreal más bien que surreal; es decir: no tiene tanta relación con lo onírico como con una ilusión bien despierta y operante. En palabras de Leopoldo de Luis «es aquella imagen lograda mediante la conjunción de un elemento artís-

\footnotetext{
38 VM, 88.

39 VM, 87.

40 VM, 88.

41 VM, 73.

42 VM, 93.

$43 \mathrm{OP}, 87$.

44 OP, 148.
} 
tico y una ilusión» ${ }^{45}$. El eximio crítico ilustra tal concepto con un análisis del poema «Ala del prestidigitador» ${ }^{46}$, análisis que no podemos seguir aquí, pero cuyas conclusiones podemos apreciar como en resumen en sus últimos versos:
«Intensa flor de nieve, diaria rosa tallada
en cuerpos de arboleda repartida
donde los signos nacen, proliferan
como detonaciones o susurros,
por culpa de una mano
con la que un miedo escribe
$y$ en la que un mirlo canta» ${ }^{47}$.

La imagen proliferante tiene un ejemplo paradigmático bien conocido. Es el poema «Noche en el grito» de La visita del mar. Según declara el propio autor, él mantuvo discusiones con Carlos Bousoño sobre la posibilidad de extender este tipo de imagen a todo un poema, y consideró un reto componerlo. El resultado, «Noche en el grito», mereció el asentimiento de Bousoño.

En palabras de Justo Jorge Padrón, «este poema, a la manera de las células del cáncer o de la radiación atómica, va expandiendo su imagen a los sucesivos versos hasta llegar a los últimos y recogerse en una pieza entera desde su núcleo central». Y añade: «Creo que este ejemplo es sintomático de una de las actitudes frecuentes que intento ante la creación» ${ }^{48}$.

El concepto de «proliferación» es querido de nuestro autor, ya que lo emplea, bien como verbo - «donde los signos nacen, proliferan» ${ }^{49}$-, bien como participio de presente — $\left\langle\right.$ Proliferante / música de reverberaciones ${ }^{50}-$. El procedimiento también lo es, ya que, aparte del ejemplo paradigmático mencionado, encuentro ciertos precedentes en «La ola ardiente te arrastra» ${ }^{51}$, y en «La invasión de los átomos» - primer poema de Los círculos del infierno ${ }^{52}$ - .

No debe maravillarnos, pues, que Icaro, uno de los más bellos símbolos del poeta,

«Vivía en las imágenes,

pero aquella ansiedad no le calmaba» ${ }^{53}$.

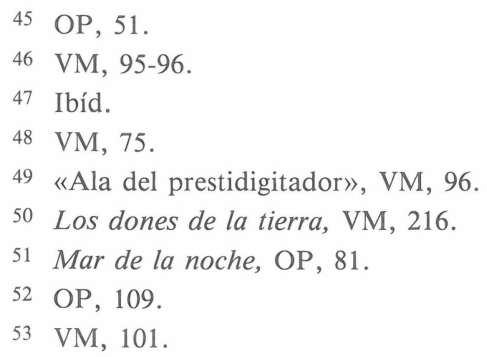




\section{Lenguaje.}

Es imposible hacer aquí un recuento medianamente satisfactorio de toda la aportación lingüística que supone la obra de Justo Jorge Padrón. Me contentaré con aludir a los rasgos más sobresalientes.

Nuestro autor confiesa que el poeta canario Domingo Velázquez le infundió ya desde las primeras tertulias en que participara «la exigencia métrica y eufónica del poema, que desde entonces me ha acompañado» ${ }^{54}$. Efectivamente, un sonoro ritmo es el acompañante inevitable de los versos blancos de Justo Jorge Padrón, y es sumamente difícil señalar en su obra algún verso que disuene como antirrítmico.

También el poeta ha manifestado su interés por «la renovación adjetival» ${ }^{55}$, y «la revitalización de adjetivos» ${ }^{56}$. Me permito señalar el uso de dos adjetivos en torno a una palabra, antecediéndola y siguiéndola respectivamente. Si la palabra en cuestión es sustantivo, serán atribuciones suyas, como en

$$
\text { «cuánta inútil palabra solidaria» }{ }^{57} \text {. }
$$

Si la palabra en cuestión es verbo, se tratará de predicados de complemento, como en

$$
\text { «cercana paseaba inasequible» }{ }^{58} \text {. }
$$

También ha escrito Justo Jorge Padrón que las correcciones que suele hacer a sus obras persiguen sobre todo «una mayor precisión y síntesis» ${ }^{59}$. En esta línea pueden inscribirse varios procedimientos como:

1) El parcialmente reprobado por la Real Academia gerundio adjetivo:

«Solamente el rumor de este futuro

y el silencio brillando

con la promesa de su plenitud» ${ }^{60}$.

«Horas que se dispersan en la inutilidad

cayendo como lluvia desde el alma a los ojos.

Sílabas susurrando junto a soledad de árboles» ${ }^{61}$.

\footnotetext{
54 OP, 12.

55 OP, 17.

56 OP, 9.

57 OP, 83.

58 OP, 90.

59 OP, 9.

60 VM, 118.

61 VM, 134.
} 
2) El uso de participios de presente originales, como «girante» ${ }^{62}$, «proliferante» ${ }^{63}$, «germinante» ${ }^{64}$, «parpadeantes» ${ }^{65}$.

3) La elipsis de verbo, como en el comienzo del poema «El día invicto del poeta» ${ }^{66}$ :

«Entregada avidez de la mirada

ante el día que gira desplegado en sí mismo.

Fundación palpitante del color».

E incluso la elipsis de verbo copulativo y conjunción conjuntamente:

«Nuestros ojos creyeron una estrella

que cruzaba lo oscuro y las distancias» ${ }^{67}$.

Es decir: se elide «que era». De «creyeron que era una estrella» se pasa así a «creyeron una estrella».

4) La aposición de sustantivos, como en

$$
\text { «Manantial crecimiento hacia lo unánime» }{ }^{68} \text {. }
$$

Es curioso señalar que aquí se ha usado un sustantivo, «manantial», de terminación parecida a la de conocidos adjetivos, como «elemental», «fundamental», «natural», etc., lo cual asegura el éxito del recurso.

Al margen ya de la anterior enumeración de fenómenos gramaticales, indicaremos que otra preocupación del poeta discurre por la vía de intentar «trascender el yo lírico y fusionarlo con el misterio universal» ${ }^{69}$. De aquí brota un interesante juego de pronombres.

1) Así por ejemplo, el hecho, ya señalado por Leopoldo de Luis ${ }^{70}$ de que el poeta emplee la segunda persona «para reflexionar sobre sí mismo», tratando así de superar su propia subjetividad. Cuando el poema de este modo formulado va dedicado a otro poeta, como «Inerme cetrería» ${ }^{71}$ a Gerardo Diego, o «El ángel caído» ${ }^{72}$ a José García Nieto, el «tú» se enriquece de sentido, pues puede tratarse también del poeta a quien va dirigido el homenaje.

2) Otras veces el poema juega con una intriga pronominal que normalmente se resuelve en el desarrollo del mismo poema, como en «Palabras para una des-

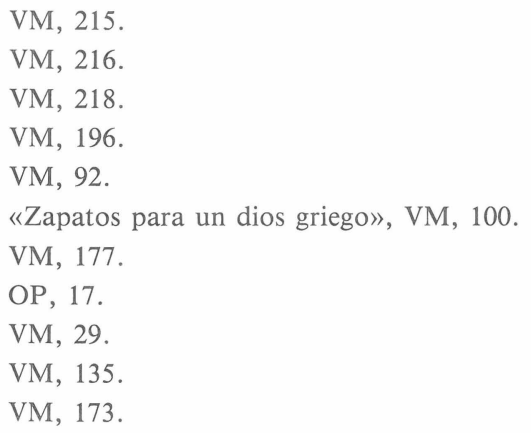


pedida» ${ }^{73}$ : «puesto que al fin ya sé que ella eres tú» ${ }^{74}$; o bien en el poema «Como quien surge del otoño» ${ }^{75}$.

O también en «Origen del asombro» ${ }^{76}$ : «La deseaba bella como un hacha...»: se trata de una mujer desnuda — ¿evocación juanramoniana? - como símbolo de la poesía. Otras veces la intriga pronominal no se resuelve, como en «El árbol negro» ${ }^{77}$, dejando prendido su misterio.

Desde el punto de vista semántico, podemos señalar la relativa preferencia de Justo Jorge Padrón por palabras iniciadas con prefijos negativos, como «inexistencia», «desmemoria», «invicto»..., y también por el concepto de «perder», tanto en su acepción transitiva - «los perdidos / nombres» ${ }^{78}$, «perdidas memorias» ${ }^{79}$, «He sabido ir perdiendo / a quien yo más amaba» ${ }^{80}$-, como en la acepción intransitiva — «aún no has perdido» ${ }^{81}$, «Perdí» ${ }^{82}$, o el título interno «Los años perdedores» ${ }^{83}$.

Por otro lado, son bien conocidos como característicos de Justo Jorge Padrón los símbolos del fuego y del mar. Y la aparición de los cuatro elementos presocráticos en su poesía.

Podemos resumir la actitud estética de Justo Jorge Padrón ante el lenguaje citando sus mismas palabras:

«Desde que te alejaste, persigo aquel momento, busco la frase exacta cuando comencé sin futuro a quererte» ${ }^{84}$.

\section{Conclusión.}

Estamos pues ante un poeta de la llamada «generación del lenguaje», que hace cumplido honor a esta denominación. El cuadrilátero padroniano - emoción, idea, imagen y lenguaje - se hace realidad vivida en la poesía de nuestro autor.

Juan Ramón definía la poesía como "casa de tiempo y de silencio que va al río de la vida», y también decía: «moro en mi poesía». Justo Jorge Padrón

VM, 185-186.

VM, 186.

OP, 87.

VM, 90-91.

VM, 163-164.

OP, 58.

OP, 109.

VM, 185.

OP, 81 .

Otesnita, OP, 280.

VM, 125.

OP, 272. 
ha invocado a la Palabra: «Palabra, son tus signos la casa que me habita» ${ }^{85}$. Con esa palabra, «su verso edifica un mar pétreo en el aire: / la catedral más pura del idioma ${ }^{86}$. Dentro de esa casa, de ese mar, de esa catedral, mora Justo Jorge Padrón.

Diremos pues, usando y combinando sus versos, y con ellos sus dos símbolos favoritos:

«El poeta es el mar frente a la nada, siempre a punto de arder en la palabra» ${ }^{87}$. 